\title{
Measurement of Red Blood Cell Zinc Concentration with Zn-Test Kit: Discrimination between Hyperthyroid Graves' Disease and Transient Thyrotoxicosis
}

\author{
NORIYO SAYAMA, KATSUMI YOSHIDA*, KOUKI MORI, HIROSHI FUKAZAWA, \\ HiRONOBU HORI, NAOKI NAKAZATO, JUN-ICHI TANI, YoshINORI NAKAGAWA, AND \\ SADAYOSHI ITO \\ *The Department of Clinical and Laboratory Medicine, and The Second Department of Internal Medicine, \\ Tohoku University School of Medicine, Sendai 980-8574, Japan
}

\begin{abstract}
We have previously reported in patients with hyperthyroidism that the red blood cell (RBC) zinc $(\mathrm{Zn})$ concentration reflects the mean thyroid hormone concentration over the preceding months. In the present study, the concentration of RBC Zn was measured by a simple and easy method with a $\mathrm{Zn}$ test Wako kit. Within-run and between-run precision were $1.4 \%$ and $1.3 \%$, respectively. The relationship between $\mathrm{RBC}$ concentration and dilution was linear. The average recovery was $103 \%$. A good correlation $(r=0.97)$ was obtained between this method and atomic absorption spectrophotometry. The mean concentration of $\mathrm{RBC} \mathrm{Zn}$ in 39 euthyroid controls was $12.6 \pm 1.3 \mathrm{mg} / l$, ranging from 10.4 to $15.1 \mathrm{mg} / l$. The RBC Zn concentrations in 38 patients with Graves' disease, in 10 patients with silent thyroiditis and in 3 patients with gestational thyrotoxicosis were $7.3 \pm 1.6(3.2-9.8), 12.0 \pm 1.6(9.5-14.2)$ and $11.8 \pm 1.7(10.5-13.7) \mathrm{mg} / l$, respectively. The concentration of RBC $\mathrm{Zn}$ was able to differentiate hyperthyroid Graves' disease from transient thyrotoxicosis except in 1 case and was a better index than TSH-binding inhibitory immunoglobulin. These results indicate that measuring RBC Zn with the Zinctest Wako kit is very useful in differentiating hyperthyroid Graves' disease from transient thyrotoxicosis.
\end{abstract}

Key words: Zinc, Red blood cell, Graves' disease, Silent thyroiditis, Gestational thyrotoxicosis

(Endocrine Journal 45: 767-772, 1998)

THERE are many reports indicating that the red blood cell (RBC) zinc $(\mathrm{Zn})$ concentration is reduced in patients with hyperthyroidism [1-3], and is inversely related to the plasma $\mathrm{T} 4$ concentration [3]. We have previously reported [4-6] in patients with hyperthyroidism that the RBC $\mathrm{Zn}$ concentration reflects a patient's mean thyroid hormone level over the preceding months as glycosilated hemoglobin does in diabetic patients

Received: April 9, 1998

Accepted: August 1, 1998

Correspondence to: Dr. Katsumi YOSHIDA, The Department of Clinical and Laboratory Medicine, Tohoku University School of Medicine, 1-1 Seiryo-machi, Aoba-ku, Sendai 980-8574, Japan
[7]. Measurement of the RBC $\mathrm{Zn}$ concentration is therefore useful in differentiating hyperthyroid Graves' disease from transient thyrotoxicosis [5, 6]. But our previously reported method for measuring the RBC Zn concentration is troublesome [4]: packed $R B C$ is block digested in the presence of acid $(0.8 \mathrm{ml}$ of concentrated nitric acid and 0.2 $\mathrm{m} l$ of concentrated perchloric acid in a micro Kjeldahl tube) and measured by atomic absorption spectrophotometry. In the present study, we describe a simple and easy method for measuring the RBC Zn concentration with a Zn-test Wako kit which is based on the method by Makino et al. [8]. 
Table 1. Thyroid function tests in patients with transient thyrotoxicosis and comparisons with those in patients with Graves' disease

\begin{tabular}{|c|c|c|c|c|c|}
\hline $\begin{array}{l}\text { Transient } \\
\text { thyrotoxicosis } \\
\text { (case no.) }\end{array}$ & Age & $\begin{array}{l}\text { Serum T4 } \\
(\mathrm{mg} / \mathrm{d} l)\end{array}$ & $\begin{array}{l}\text { Serum T3 } \\
(\mathrm{ng} / \mathrm{d} l)\end{array}$ & $\begin{array}{c}\text { RAIU } \\
(\%)\end{array}$ & $\begin{array}{l}\text { TBII } \\
(\%)\end{array}$ \\
\hline 1. silent* & 29 & 17.0 & 245 & ND & 7 \\
\hline 2. silent & 19 & 14.0 & 238 & 1.5 & -9 \\
\hline 3. silent & 35 & $(2.2)^{\#}$ & $(5.3)^{\#}$ & 0.4 & 5 \\
\hline 4. silent & 32 & $(2.4)^{\#}$ & $(6.2)^{\#}$ & 0.3 & -2 \\
\hline 5. silent & 37 & 20.0 & 276 & 0.7 & 8 \\
\hline 6. silent & 70 & $(4.4)^{\#}$ & $(9.6)^{\#}$ & 0.3 & 0 \\
\hline 7. silent & 31 & $10.9(2.3)^{\#}$ & $192(5.4)^{\#}$ & ND & -2 \\
\hline 8. silent & 29 & 16.5 & 287 & 0.2 & ND \\
\hline 9. silent & 29 & 17.0 & 387 & 1.4 & -2 \\
\hline 10. silent & 30 & 24.0 & 406 & 3.0 & 6 \\
\hline 11. gestational ${ }^{* *}$ & 29 & 19.7 & 220 & ND & 1 \\
\hline 12. gestational & 36 & $15.1(2.6)^{\#}$ & $142(5.8)^{\#}$ & ND & 0 \\
\hline 13. gestational & 26 & 24.0 & 220 & ND & 0 \\
\hline mean $\pm \mathrm{SD}$ & & $\underline{17.8 \pm 4.2}$ & $\underline{261 \pm 82^{\mathrm{a}}}$ & $\underline{1.4 \pm 1.9^{\mathrm{a}}}$ & $\underline{0.8 \pm 4.6^{\mathrm{a}}}$ \\
\hline \multicolumn{6}{|c|}{ Graves' disease $(n=38)$} \\
\hline mean $\pm S D$ & & $20.3 \pm 3.5$ & $432 \pm 170$ & $60 \pm 20$ & $32 \pm 23$ \\
\hline range & & $14.0-24.0$ & $272-800$ & $27-90$ & $-1-81$ \\
\hline \multicolumn{6}{|c|}{ normal control $(n=39)$} \\
\hline mean $\pm \mathrm{SD}$ & & $7.3 \pm 1.3$ & $98 \pm 13$ & ND & ND \\
\hline range & & $5.3-10.0$ & $73-114$ & & \\
\hline normal range & & $4.5-12.0$ & $70-180$ & $10-40$ & $<10$ \\
\hline
\end{tabular}

silent $^{*}$, silent thyroditis; gestational ${ }^{* *}$, gestational thyrotoxicosis; ( )\#, serum free hormone concentration (free $\mathrm{T} 4 \mathrm{ng} / \mathrm{d} l$; free $\mathrm{T} 3 \mathrm{pg} / \mathrm{ml}$ ); ND, not determined. ${ }^{\mathrm{a}}: P<0.01 \mathrm{vs}$. Graves' disease.

\section{Materials and Methods}

Heparinized venous blood was obtained from 39 healthy volunteers, 38 untreated patients with hyperthyroid Graves' disease, and 13 patients with transient thyrotoxicosis ( 10 with silent thyroiditis and 3 with gestational thyrotoxicosis) (Table 1). The diagnosis of Graves' disease was based on high serum T4 and T3 levels, a suppressed TSH concentration, diffuse goiter, and normal or high thyroid radioactive iodine uptake (RAIU) and/or positive TSH-binding inhibitory immunoglobulin (TBII). The diagnosis of silent thyroiditis was based on clinical and laboratory findings including a transient increase in serum T4 and T3 levels, a suppressed serum TSH concentration, and a marked depression of RAIU (patients Nos. 2-6, 810 ), or transient thyrotoxicosis followed by transient hypothyroidism during the postpartum nursing period (patient Nos. 1, 7). None had pain in the thyroid gland. The diagnosis of gestational thyrotoxicosis was based on high T4 and T3 levels at 2-4 months of gestation, negative TBII, and spontaneous recovery in the second trimester. The hemoglobin $(\mathrm{Hb})$ concentrations were all more than $10 \mathrm{~g} / \mathrm{d} l$.

RBC Zn was measured with a Zn-test Wako kit. Samples (packed RBC diluted with 10 volumes of distilled water, $0.5 \mathrm{ml}$ ) and trichloroacetic acid solution $(0.5 \mathrm{ml})$ were pipetted into tubes and centrifuged for $10 \mathrm{~min}$ at $3000 \mathrm{rpm}$. Supernatants $(0.5 \mathrm{ml})$ were transferred into each tube, and color reagents were added. Then the absorbance at 560 $\mathrm{nM}$ was measured within $30 \mathrm{~min}$. The concentration of iron in the supernatants was less than $100 \mathrm{mg} / \mathrm{d} l$. Iron concentrations less than 1 $\mathrm{mg} / \mathrm{d} l$ had no effect on the $\mathrm{Zn}$ concentration in this kit. The RBC $\mathrm{Zn}$ concentration was also measured by atomic absorption spectrophotometry 
$[4,5]$ in 13 patients to study the correlation with this method. Total serum T4 and T3 concentrations were measured by EIA; their normal ranges were $4.5-12 \mathrm{mg} / \mathrm{d} l$ and $70-180 \mathrm{ng} / \mathrm{d} l$, respectively. Serum free T4 and free T3 concentrations were measured by RIA; their normal ranges were $0.7-$ $1.8 \mathrm{ng} / \mathrm{d} l$ and $2.45-4.65 \mathrm{pg} / \mathrm{ml}$, respectively. The serum TSH concentration was measured by a highly sensitive immunoradiometric assay. The normal range was $0.3-3.5 \mathrm{mU} / \mathrm{ml}$. TBII was measured in 37 patients with Graves' disease and 12 patients with transient thyrotoxicosis with a TSH receptor assay kit (RSR Ltd., Pentwyn, Cardiff, UK). The normal range was less than $10 \%$. The RAIU (normal range, 10-40\%) was determined in 30 patients with Graves' disease and 8 patients with silent thyroiditis. It was not determined in patients with silent thyroiditis during breast-feeding or in patients with gestational thyrotoxicosis.

Statistical analyses were performed by means of Student's $t$-test. Correlations between two variables were calculated by linear regression analysis.

\section{Results}

Table 1 shows thyroid function tests in the patients with transient thyrotoxicosis compared with those in untreated Graves' disease and normal subjects. The mean serum T3 concentration was significantly $(P<0.01)$ higher in patients with Graves' disease than those in transient thyrotoxicosis, but there was a considerable overlap. There was no significant difference in the mean plasma T4 concentration. The plasma TSH concentrations were all less than the lower limit of sensitivity of $0.04 \mathrm{mU} / \mathrm{ml}$ in patients with Graves' disease and transient thyrotoxicosis.

TBII was negative in all 12 patients with transient thyrotoxicosis, but it was also negative in $16 \%$ (6/ 37 ) of Graves' disease. The RAIU value was less than $3 \%$ in patients with silent thyroiditis and more than $28 \%$ in patients with Graves' disease.

The concentration of RBC Zn measured with Zntest Wako kits was correlated to a significant extent $(\mathrm{r}=0.97)$ with that measured by atomic absorption spectrophotometry (Fig. 1). The relationship between the RBC concentration and dilution was linear. The average recovery was found to be $103 \%$. Within-run and between-run precision were $1.4 \%$

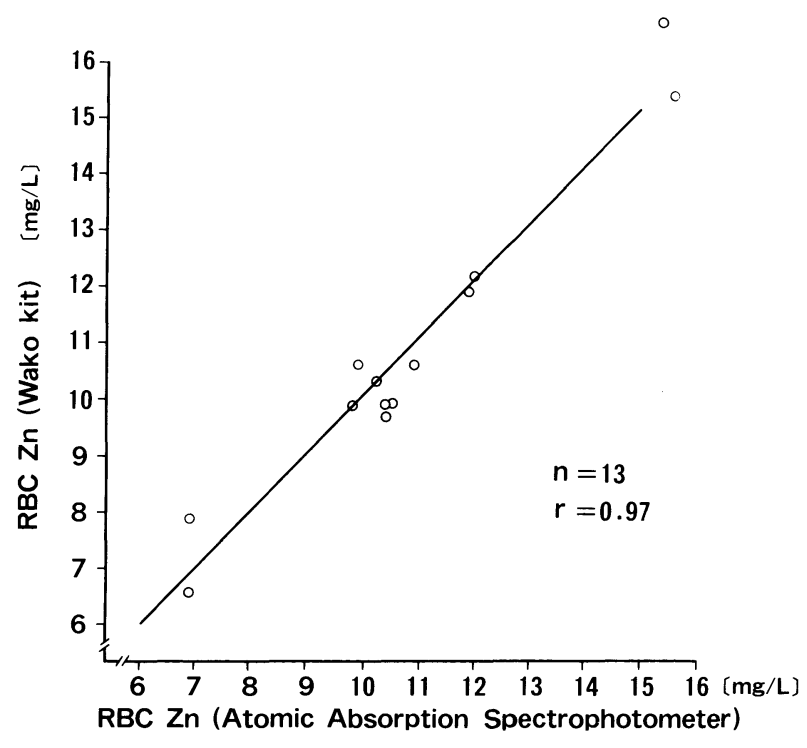

Fig. 1. Correlation of RBC Zn concentrations measured with a $\mathrm{Zn}$-test Wako kit and an atomic absorption spectrophotometer.

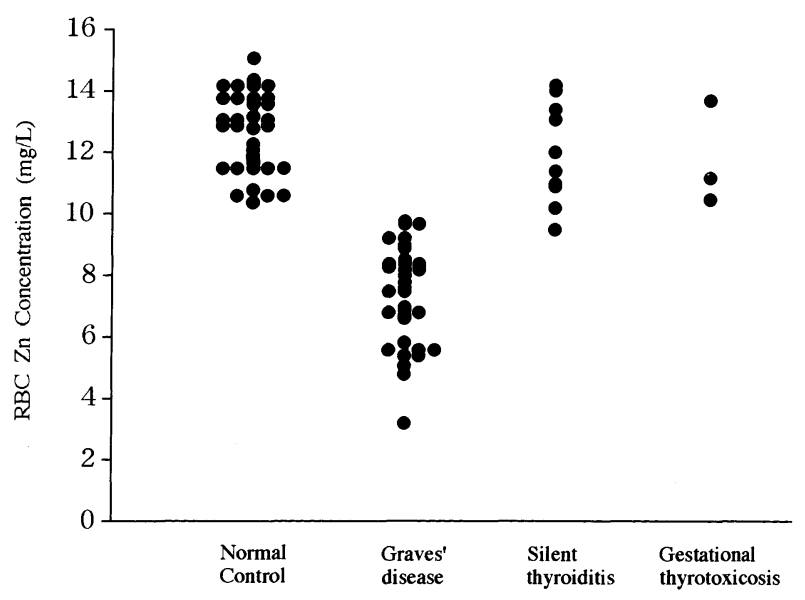

Fig. 2. RBC Zn concentrations in normal subjects and patients with thyroid diseases.

and $1.3 \%$, respectively.

The RBC Zn levels in control subjects and in patients with transient thyrotoxicosis are shown in Fig. 2. The mean concentration of $\mathrm{RBC} \mathrm{Zn}$ in 39 euthyroid controls was $12.6 \pm 1.3 \mathrm{mg} / l$, ranging from 10.4 to $15.1 \mathrm{mg} / \mathrm{l}$. The normal range defined as the mean $\pm 2 \mathrm{SD}$ was $10.0-15.2 \mathrm{mg} / l$. The RBC $\mathrm{Zn}$ concentration was decreased in all 38 patients with Graves' disease. It was normal in 12/13 
patients with transient thyrotoxicosis and one patient had a marginally low value $(9.5 \mathrm{mg} / l)$.

\section{Discussion}

Seino reported that the RBC Zn concentration in patients with iron deficiency anemia, whose hemoglobin concentration is more than $7.5 \mathrm{~g} / \mathrm{d} l$, is almost within normal limits when expressed per $\mathrm{ml}$ of packed RBCs, but it is lower per cell and is higher per gram of $\mathrm{Hb}$, respectively [9]. Valberg et al. reported that the RBC Zn concentration in these patients is decreased per cell, but the level per volume and per gram of $\mathrm{Hb}$ is within normal limits [10]. In the present study we therefore expressed the RBC Zn concentration per liter of packed RBCs.

Silent thyroiditis accounts for $5-10 \%$ of all cases of thyrotoxicosis [11]. Although a thyroid RAIU value is most useful in differentiating hyperthyroid Graves' disease from silent thyroiditis, this test can be performed in only a limited number of institutions. TBII is positive in patients with Graves' disease in $80-90 \%$, but it is also positive in patients with silent thyroiditis in about $15 \%$ [12]. Treatment with antithyroid drugs for silent thyroiditis is inappropriate.

Gestational thyrotoxicosis is common during the first trimester of pregnancy. Treatment with antithyroid drugs is needed in patients with hyperthyroid Graves' disease with pregnancy, since untreated hyperthyroidism is associated with increased fetal loss, with premature labor, and with low birth weight [13]. On the other hand, the value of antithyroid drugs in gestational thyrotoxicosis is not established, and their use should probably be reserved for the later stage of pregnancy. Therefore, differentiation between these two conditions is important. As mentioned above, TBII is positive in only $80-90 \%$ of Graves' disease. Thyroid stimulating activity is positive not only in Graves' disease, but also in gestational thyrotoxicosis [14]. In the present study, TBII was negative in all 12 patients with transient thyrotoxicosis tested, but TBII was negative in $16 \%$ $(6 / 37)$ of Graves' disease patients. Therefore, in some cases it is difficult to differentiate Graves' disease from transient thyrotoxicosis due to the existence of silent thyroiditis and gestational thyrotoxicosis.
We recently reported that thyroid hormone inhibits the synthesis of carbonic anhydrase I (CAI) isoenzyme in human erythroleukemic $\mathrm{YN}-1$ cells [15] and in the normal developing RBC (burstforming unit erythroid-derived cells) [16] at the mRNA level [17]. Since most of the zinc in RBC is present as a complex with CAI [18], the RBC Zn concentration correspondingly decreases in patients with hyperthyroidism [1-3]. Since the life span of RBC is 120 days, we serially measured both RBC $\mathrm{CAI}$ and $\mathrm{Zn}$ concentrations in hyperthyroid patients before and after treatment with antithyroid drugs and reported that both RBC CAI [19] and Zn [4] concentrations reflect the mean thyroid hormone level over the preceding months. Because the changes in the RBC Zn concentration after changes in thyroid function take time to develop, at their initial presentation patients with acute thyrotoxicosis due to subacute thyroiditis and silent thyroiditis have a normal $\mathrm{RBC} \mathrm{Zn}$ concentration [5, 6]. Lao et al. [20] reported that measuring the RBC Zn concentration allows discrimination between preexisting hyperthyroidism and gestational thyrotoxicosis. Recently Ozawa reported in a preliminary form that measurement of the RBC Zn concentration by atomic absorption spectrophotometry is very useful in differentiating hyperthyroid Graves' disease from transient thyrotoxicosis [21].

In the present study we measured the RBC $\mathrm{Zn}$ concentration with a Zn-test Wako kit. This kit was developed to measure the serum $\mathrm{Zn}$ concentration. Since the RBC Zn concentration is about 10 times more than that in serum, samples were diluted with 10 volumes of distilled water before the assay. The level of RBC Zn measured by this method was almost same as that measured by atomic absorption spectrophotometry. Furthermore, the dilution test, recovery test and within-run and between-run precision were all satisfactory. Because the value was not influenced by iron, we think that the RBC Zn concentration can be measured precisely by means of this kit. It has several advantages over the previous atomic absorption spectrophotometric method. Time consuming acid treatment is omitted and an atomic absorption spectrophotometer is unnecessary. It is not expensive (50 tests for 12,000 yen), is simple and easy to perform and the results are obtained within $2 \mathrm{~h}$. 
In the present study, The RBC Zn concentration was decreased in patients with hyperthyroid Graves' disease, as reported previously [4]. The $\mathrm{RBC} \mathrm{Zn}$ concentration was in the normal range in all patients except one with transient thyrotoxicosis. The RBC Zn concentration may therefore be a better index than TBII to differentiate hyperthyroid Graves' disease from transient thyrotoxicosis. These results indicate that measuring $\mathrm{RBC} \mathrm{Zn}$ with this kit is clinically very useful.

\section{Acknowledgment}

This work was supported in part by Grant-inAid for Scientific Research No. 09671017 from the Ministry of Education, Science and Culture of Japan.

\section{References}

1. Aihara K, Nishi $Y$, Hatano S, Kihara M, Yoshimitsu K, Takeichi N, Ito T, Ezaki H, Usui T (1984) Zinc, copper, manganese, and selenium metabolism in thyroid disease. Am J Clin Nutr 40: 26-35.

2. Pangaro JA, Weinstein $M$, Devetak MC, Soto RJ (1974) Red cell zinc and red cell zinc metalloenzymes in hyperthyroidism. Acta Endocrinol (Copenh) 76: 645-650.

3. Dolev E, Deuster PA, Solomon B, Trostmann UH, Wartofsky L, Burman KD (1988) Alterations in magnesium and zinc metabolism in thyroid disease. Metabolism 37: 61-67.

4. Yoshida K, Kiso Y, Watanabe T, Kaise K, Kaise N, Itagaki Y, Yamamoto M, Sakurada T, Yoshinaga K (1990) Erythrocyte zinc in hyperthyroidism: Reflection of integrated thyroid hormone levels over the previous few months. Metabolism 39: 182186.

5. Yoshida K, Kiso Y, Watanabe T, Kaise K, Kaise N, Fukazawa H, Yamamoto M, Sakurada T, Yoshinaga K (1990) Erythrocyte zinc concentration in patients with subacute thyroiditis. I Clin Endocrinol Metab 70: 788-791.

6. Yoshida K, Kiso Y, Watanabe T, Kaise K, Kaise N, Fukazawa H, Mori K, Abe K, Yoshinaga K (1991) Clinical utility of red blood cell carbonic anhydrase I and zinc concentrations in patients with thyroid diseases. Metabolism 40: 1048-1051.

7. Gabbay KH, Hasty K, Breslow JL, Ellison RC, Bunn HF, Gallop PM (1977) Glycosylated hemoglobins and long-term blood glucose control in diabetes mellitus. J Clin Endocrinol Metab 44: 859-864.

8. Makino T, Saito M, Horiguchi D, Kina K (1982) A highly sensitive calorimetric determination of serum zinc using water-soluble pyridylazo dye. Clin Chim Acta 120: 127-135.

9. Seino M (1976) Determination of erythrocyte zinc by atomic absorption spectrophotometry: Its significance in iron deficiency anemia. Hokkaido Igaku Zasshi 51: 59-72 (In Japanese).

10. Valberg LS, Holt JM, Brown GM (1965) Sodium, potassium, calcium, magnesium, copper, and zinc composition of erythrocytes in vitamin $B_{12}$ deficiency and iron deficiency. / Clin Invest 44: 12251233.

11. Lazarus JH (1996) Silent thyroiditis and subacute thyroiditis. In: Braverman LE, Utiger RD (eds) Werner and Ingbar's The Thyroid. 9th ed, Lippincott-Raven, Philadelphia: 577-591.

12. Morita T, Tamai H, Oshima A, Mukuta T, Fukata S, Kuma K, Kumagai LF, Nagataki S (1990) The occurrence of thyrotropin ding-inhibiting immunoglobulins and thyroid-stimulating antibodies in patients with silent thyroiditis. J Clin Endocrinol Metab 71: 1051-1055.

13. Drury MI (1986) Hyperthyroidism and pregnancy. I $R$ Soc Med 79: 317-318

14. Kimura M, Amino N, Tamaki H, Ito E, Mitsuda N, Miyai K, Tanizawa O (1993) Gestational thyrotoxicosis and hyperemesis gravidarum: Possible role of hCG with high stimulating activity. Clin Endocinol 38: 345-350.

15. Kikuchi K, Yoshida K, Endo K, Aizawa Y, Fukazawa H, Mori K, Abe K (1994) Effects of thyroid hormone on carbonic anhydrase I levels in human erythroid (YN-1) cells. J Clin Endocrinol Metab 79: 71-75.

16. Sayama N, Yoshida K, Endo K, Kiso $Y$, Fukazawa H, Mori K, Kikuchi K, Aizawa Y, Hori H, Abe K (1996) Effects of thyroid hormone on carbonic anhydrase I concentration in human erythroid burst-forming unit-derived cells. Endocrinology 137: 1828-1832.

17. Hori H, Yoshida K, Fukazawa H, Kiso Y, Sayama N, Mori K, Aizawa Y, Tani ], Nakagawa Y, Abe K (1998) Effects of thyroid hormone on carbonic anhydrase I gene expression in human erythroid cells. Thyroid 8: 525-531.

18. Ohno H, Doi R, Yamamura K, Yamashita K, lizuka $\mathrm{S}$, Taniguchi N (1985) A study of zinc distribution in erythrocytes of normal humans. Blut 50: 113116.

19. Kiso $Y$, Yoshida K, Kaise K, Kaise N, Fukazawa H, Mori K, Abe K, Yoshinaga K (1991) Erythrocyte carbonic anhydrase-I concentrations in patients with 
Graves' disease and subacute thyroiditis reflect integrated thyroid hormone levels over the previous few months. J Clin Endocrinol Metab 72: 515-518.

20. Lao TTH, Chin RKH, Swaminathan R, Panesar NS, Cockram CS (1987) Erythrocyte zinc in differential diagnosis of hyperthyroidism in pregnancy: A preliminary report. Brit Med J 294: 1064-1065.

21. Ozawa Y (1997) Diagnosis of Graves' disease differentiation from destructive thyroiditis. Naika (Internal Medicine) 80: 826-830 (In Japanese). 